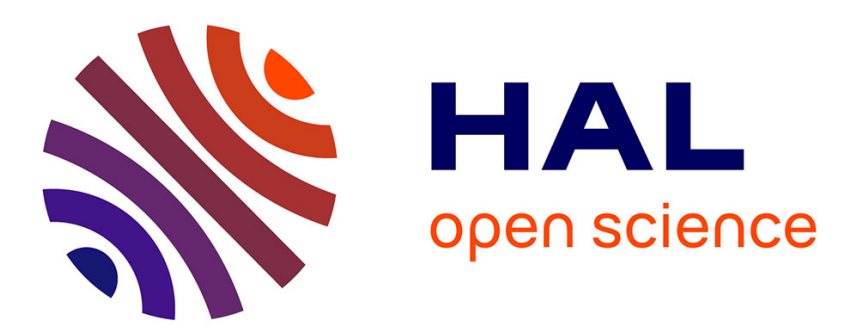

\title{
New lead-free perovskite relaxor ceramics derived from BaTiO3 and containing scandium
}

\author{
Annie Simon, Jean Ravez
}

\section{To cite this version:}

Annie Simon, Jean Ravez. New lead-free perovskite relaxor ceramics derived from BaTiO3 and containing scandium. Journal of Advanced Dielectrics, 2011, 1 (2), pp.251-255. 10.1142/S2010135X11000240 . hal-00602024

\section{HAL Id: hal-00602024 https://hal.science/hal-00602024}

Submitted on 3 Feb 2012

HAL is a multi-disciplinary open access archive for the deposit and dissemination of scientific research documents, whether they are published or not. The documents may come from teaching and research institutions in France or abroad, or from public or private research centers.
L'archive ouverte pluridisciplinaire HAL, est destinée au dépôt et à la diffusion de documents scientifiques de niveau recherche, publiés ou non, émanant des établissements d'enseignement et de recherche français ou étrangers, des laboratoires publics ou privés. 


\title{
NEW LEAD-FREE PEROVSKITE RELAXOR CERAMICS DERIVED

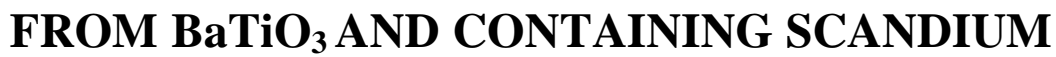

\author{
ANNIE SIMON and JEAN RAVEZ \\ CNRS, Université de Bordeaux, ICMCB, 87 avenue A. Schweitzer \\ 33608, PESSAC, France \\ simon@icmcb-bordeaux.cnrs.fr
}

\begin{abstract}
New lead-free compositions of $\mathrm{ABO}_{3}$ perovskite type were synthesized in the $\mathrm{BaTi}_{1-\mathrm{x}}\left(\mathrm{Nb}_{1 / 2} \mathrm{Sc}_{1 / 2}\right)_{\mathrm{x}} \mathrm{O}_{3}$ $(0 \leq \mathrm{x} \leq 1)$ system, with regards to the comparable electronic configurations of the various 6coordinated cations. Special solid state reaction was used. The effect of the replacement of titanium by scandium and niobium in the B-site on structural and dielectric properties was investigated. For this, we have used X-ray diffraction and dielectric characterizations. Dielectric measurements performed on ceramics with $0 \leq \mathrm{x} \leq 0.25$ composition revealed that the small change in composition from $\mathrm{BaTiO}_{3}$ has a strong influence on the dielectric properties: fast decreasing of the ferroelectric transition temperature for low values of $\mathrm{x}$ and evolution from classical ferroelectric for $0 \leq \mathrm{x} \leq 0.075$ to relaxor behavior for $0.075<\mathrm{x} \leq 0.25$.
\end{abstract}

Keywords: lead-free, perovskite, relaxor, $\mathrm{BaTiO}_{3}$, scandium.

\section{Introduction}

In $\mathrm{AMO}_{3}$-type perovskites, relaxor behavior mainly occurs in lead-based compositions (PMN, PSN, PIN, PLZT, etc...) with more than one type of ion occupying the equivalent 6-coordination number (C.N.) crystallographic site. ${ }^{1}$ Lead-free compositions could be of great interest for environment-friendly applications (dielectric for capacitors, actuators, etc...). Studies have therefore been performed in detail on ceramics with $\mathrm{BaTiO}_{3}$-derived compositions. ${ }^{2-23}$ Thanks to frequency dielectric studies, these materials have been shown to be classical or relaxor ferroelectrics depending on both the composition and the type of ionic substitution.

The aim of the present work was to prepare and to characterize some new lead-free ceramics with perovskite compositions derived from $\mathrm{BaTiO}_{3}$ and with scandium content. In spite of the relative proximity of the electronic configuration of $\mathrm{Ti}^{4+}\left(3 \mathrm{~d}^{2} 4 \mathrm{~s}^{2}\right)$ and $\mathrm{Sc}^{3+}\left(3 \mathrm{~d}^{1} 4 \mathrm{~s}^{2}\right)$ neither dielectric properties nor crystallographic study was previously performed. However such element was already used in the case of $\mathrm{Pb}\left(\mathrm{Sc}_{1 / 2} \mathrm{Nb}_{1 / 2}\right) \mathrm{O}_{3}$ which is a well-known lead content relaxor. ${ }^{24,25}$

\section{Preparation}

The various compositions were prepared by solid state reactions from pecursors with mixing, grinding, calcination and sintering to obtain ceramics the most compact as possible. In a first time, such a process was conceivable using here the various departure used compositions $\mathrm{BaCO}_{3}(\mathrm{Cerac} 99.9 \%), \mathrm{TiO}_{2}(\mathrm{Cerac} 99.9 \%), \mathrm{Nb}_{2} \mathrm{O}_{5}(\mathrm{Cerac}$ 99.99\%) and $\mathrm{Sc}_{2} \mathrm{O}_{3}$ (Fluka 99.9\%, containing less than $0.01 \% \mathrm{Yb}_{2} \mathrm{O}_{3}$ and less than $0.02 \% \mathrm{Y}_{2} \mathrm{O}_{3}$ ) by solid state synthesis using the following chemical reaction:

$$
\mathrm{BaCO}_{3}+(1-\mathrm{x}) \mathrm{TiO}_{2}+(0.5 \mathrm{x} / 2) \mathrm{Nb}_{2} \mathrm{O}_{5}+(0.5 \mathrm{x} / 2) \mathrm{Sc}_{2} \mathrm{O}_{3} \rightarrow \mathrm{BaTi}_{1-\mathrm{x}}\left(\mathrm{Nb}_{1 / 2} \mathrm{Sc}_{1 / 2}\right)_{\mathrm{x}} \mathrm{O}_{3}+\mathrm{CO}_{2} \text {. }
$$

In spite of a systematic study with different parameters of preparation (grinding type, reaction temperature and times, annealing or quenching), it was not possible to obtain single phase ceramics; the $\mathrm{BaTiO}_{3}$ composition was always present with the solid solution. This result was well evidenced by dielectric measurements where the peak of relative real permittivity $\varepsilon_{r}^{\prime}$ was always present at $\mathrm{T}_{\mathrm{C}}\left(\mathrm{BaTiO}_{3}\right)=400 \mathrm{~K}$. 
Solid state process reactions remaining, we were successful to obtain a monophased solid solution carrying out the previous mixing and intimate grinding with three steps: firstly $\mathrm{Nb}_{2} \mathrm{O}_{5}+\mathrm{Sc}_{2} \mathrm{O}_{3}$, then we add $\mathrm{TiO}_{2}$ to the previous mixing and in the end we add $\mathrm{BaCO}_{3}$ to the transition oxides. Thermal treatments were then carried out: a calcination for $15 \mathrm{~h}$ at $1250^{\circ} \mathrm{C}$ which ensure the chemical reaction followed by $4 \mathrm{~h}$ sintering at 1450 or $1500^{\circ} \mathrm{C}$ depending on the composition. Both heat treatments were carried out under a dry oxygen atmosphere. This process was necessary due to our relative low value of temperature heat treatments compared to the refractory effect of $\mathrm{Sc}_{2} \mathrm{O}_{3}\left(\mathrm{~T}_{\text {melting }}\left(\mathrm{Sc}_{2} \mathrm{O}_{3}\right) \sim 2430^{\circ} \mathrm{C}\right){ }^{26}$

\section{X-ray diffraction study}

Powder X-ray diffraction measurements were performed on a Philips diffractometer using $\mathrm{Cu}-\mathrm{K} \alpha$ radiation at room temperature. For compositions $0 \leq \mathrm{x} \leq 1$, a pure perovskite X-ray diffraction appeared in each case. For instance, the figure 1 gives the $\mathrm{X}$-ray pattern for the composition corresponding to $\mathrm{x}=0.25$.The diameter shrinkages $\Delta \Phi / \Phi\left[\Phi_{\text {init }}-\Phi_{\text {fin }} / \Phi_{\text {init. }}\right]$ of the ceramics were in the range 14-16\%. The densities of the sintered samples were $95-97 \%$ of the theoretical values. No sintering additives were here used.

\section{Dielectric measurements}

Dielectric measurements were performed on ceramic discs after deposition of gold electrodes on the circular faces by dc sputtering. The real and imaginary parts of the permittivity $\varepsilon_{r}^{\prime}$ and $\varepsilon^{\prime \prime}{ }_{r}$ were measured under helium as a function of both temperature $(85-500 \mathrm{~K})$ and frequency $\left(10^{2}-2.10^{5} \mathrm{~Hz}\right)$ using a Wayne-Kerr component analyzer.

For compositions with $0 \leq \mathrm{x} \leq 0.075$, the ceramics showed conventional ferroelectric properties with a sharp maximum of $\varepsilon_{\mathrm{r}}^{\prime}$ at the Curie temperature $\mathrm{T}_{\mathrm{C}}$ and a small anomaly at $\mathrm{T}_{1}$ corresponding to the orthorhombictetragonal transition in the ferroelectric region. There was a small dielectric frequency dispersion, but the value of $\mathrm{T}_{\mathrm{C}}$ was not dependent on frequency. As an example we reported on figure 2 the result obtained for ceramics corresponding to $\mathrm{x}=0\left(\mathrm{BaTiO}_{3}\right)$ and $\mathrm{x}=0.025$. The values of the Curie temperature vary slowly from 400 to $320 \mathrm{~K}$ as $\mathrm{x}$ increased. The temperature dependence of $1 / \varepsilon_{\mathrm{r}}^{\prime}$ at $1 \mathrm{kHz}$ was also in good agreement with a CurieWeiss law in the paraelectric region $\left(\mathrm{T}>\mathrm{T}_{\mathrm{C}}\right)$. For example, figure 3 shows the temperature dependence of $1 / \varepsilon_{\mathrm{r}}^{\prime}$ for a ceramic with composition $\mathrm{x}=0.05$. Here the transition was of first order $\left(\mathrm{T}_{\mathrm{C}}-\mathrm{T}_{0} \approx 20 \mathrm{~K}\right.$, where $\mathrm{T}_{0}$ is the CurieWeiss temperature), as it was also for pure $\mathrm{BaTiO}_{3}{ }^{27}$

For compositions $0.075<\mathrm{x} \leq 0.25$ only one broad peak of $\varepsilon_{\mathrm{r}}^{\prime}$ was observed; in fact, the limit value 0.25 corresponds only to that where dielectric anomalies were detectable by us with regards to our measurement limitation temperature $(85 \mathrm{~K})$. For example, figure 4 shows the temperature and frequency dependences of $\varepsilon_{\mathrm{r}}$ for $\mathrm{x}=0.15$. In addition, the temperature $\mathrm{T}_{\mathrm{m}}$ of $\varepsilon_{\mathrm{r}}^{\prime}$ maximum was shifted to higher values at greater frequencies. A frequency dispersion took place for $\mathrm{T} \leq \mathrm{T}_{\mathrm{m}}$, the value of $\varepsilon_{\mathrm{r}}^{\prime}$ decreasing when the frequency increased. The temperature and frequency variations of $\varepsilon^{\prime \prime}$ were also specific (Fig. 5): the temperature $T_{m}$ of $\varepsilon^{\prime \prime}{ }_{r}$ maximum was shifted to higher values at greater frequencies, but contrary to the evolution of $\varepsilon_{\mathrm{r}}^{\prime}$, the evolution of the frequency dispersion was here characterized by an increase of $\varepsilon^{\prime \prime}{ }_{r}$ when frequency increased. In addition there was a deviation from the Curie-Weiss law. The value of the Curie-Weiss temperature $T_{0}$ was greater than that of $T_{m}$ $\left(\mathrm{T}_{0}>\mathrm{T}_{\mathrm{m}}\right)$ and that of $\mathrm{T}_{\text {dev. }}-\mathrm{T}_{\mathrm{m}}$ was about of $104 \mathrm{~K}$ for the composition corresponding to $\mathrm{x}=0.15$ (Fig. 6).

A dielectric dispersion was evidenced leading to a Vogel-Fulcher behavior. It has been found that in many relaxors the relationship between the frequency $f$ of the ac measurement field and the temperature $T_{m}$ can be described using the Vogel-Fulcher relationship: $\log f=\log f_{0}-E_{a} /\left(k_{B}\left(T_{m}-T_{V F}\right)\right)$ where $f_{0}$ is the high temperature extrapolation of the attempt frequency, $\mathrm{E}_{\mathrm{a}}$ the activation energy, $\mathrm{k}_{\mathrm{B}}$ the Boltzman constant and $\mathrm{T}_{\mathrm{VF}}$ the static freezing temperature. ${ }^{28-30}$ This is known to be one of the characteristics of relaxor systems. For example, $\mathrm{T}_{\mathrm{VG}}=88 \mathrm{~K}$ for $\mathrm{x}=0.15$. Figure 7 illustrates the good fit of the data $\log \mathrm{f} v \mathrm{~T}_{\mathrm{m}}$ with a Vogel-Fulcher law. The fitting parameters of Vogel-Fulcher relation were:

$$
\mathrm{E}_{\mathrm{a}}=0.255 \mathrm{eV}, \mathrm{f}_{\mathrm{o}}=2.7 .10^{22} \mathrm{~Hz} \text { and } \mathrm{T}_{\mathrm{f}}=87.7 \mathrm{~K}
$$

All these dielectric characteristics are typical of a relaxor behavior for $0.075<\mathrm{x} \leq 0.25 .{ }^{1}$ As $\mathrm{x}$ increased, the value of $T_{\text {dev. }}-T_{m}$ increased, implying that the relaxor effect also increased (Table 1). This is known to be one of the characteristics of relaxor systems. 
Figure 8 shows the composition variation of $\mathrm{T}_{\mathrm{C}}$ (or $\mathrm{T}_{\mathrm{m}}$ ) at $1 \mathrm{kHz}$ for the solid solution $\mathrm{BaTi}_{1-\mathrm{x}}\left(\mathrm{Nb}_{1 / 2} \mathrm{Sc}_{1 / 2}\right)_{\mathrm{x}} \mathrm{O}_{3}$. The value of $\mathrm{T}_{\mathrm{C}}$ or $\mathrm{T}_{\mathrm{m}}$ decreased from $\mathrm{T}_{\mathrm{C}}\left(\mathrm{BaTiO}_{3}\right)=400 \mathrm{~K}$ as $\mathrm{x}$ increased. We also obtained an increase in $\Delta \mathrm{T}_{\mathrm{m}}$ when $\mathrm{x}$ increased. These results are in good agreement with those previously obtained. $^{23}$

\section{Conclusion}

Ceramics samples of niobium and scandium doped barium titanate with general composition $\mathrm{BaTi}_{1-\mathrm{x}}\left(\mathrm{Nb}_{1 / 2} \mathrm{Sc}_{1 / 2}\right)_{\mathrm{x}} \mathrm{O}_{3}$ have been elaborated by a special solid state reaction method. It was shown by $\mathrm{X}$-ray diffraction at room temperature that the structure of the compounds is of perovskite type for $0 \leq \mathrm{x} \leq 1$. Dielectric measurements show that the permittivity peak is sharp, without frequency dependence for $0 \leq \mathrm{x} \leq 0.075$ : it corresponds to a typical ferroelectric-paraelectric phase transition. For compositions in the region $0.075<\mathrm{x} \leq 0.25$, the $\varepsilon_{\mathrm{r}}$ peak becomes diffuse and characterizes a relaxor behaviour. The degree of relaxor character represented by $\Delta \mathrm{T}_{\mathrm{m}}$ increases when the ratio of $\mathrm{Nb}$ and $\mathrm{Sc}$ increases up to $\Delta \mathrm{T}_{\mathrm{m}}=20 \mathrm{~K}$ for $\mathrm{x}=0.25$. Up to this last value no permittivity anomaly was detected due only to our low temperature dielectric measurement limitations.

\section{References}

1. L.E. Cross, Ferroelectrics 151, 305 (1994).

2. T. Mitsui and W.B. Westphal, Phys. Rev. 124(5), 1354 (1961).

3. G. Shirane and A Takeda, J. Phys. Soc. Jpn. 6, 128 (1951).

4. D. Hennings, A. Schnell and G. Simon, J. Am. Ceram. Soc. 65(11), 539 (1982).

5. J. Ravez and A. Simon, Eur. J. Solid State Inorg. Chem. 34, 1199 (1997).

6. N. Yasuda, H. Ohwa and S. Asano, Jpn. J. Appl. Phys. 35, 5099 (1996).

7. Zhi Yu, Chen Yang, Zhi Jing, P.M. Vilarhino and J.L. Baptista, J. Phys.:Condensed Matter 9, 3081 (1997).

8. E. C. Subbarao and G. Shirane, J. Am. Ceram. Soc. 42, 279 (1959).

9. V.A. Isupov, Bull. Acad. Sci. USSR. Ser. 21, 404 (1957).

10. V.V. Lemanov, N.V. Zaïtseva, E.P. Smirnova and P.P. Syrnikov, Ferroelectric Lett. 19, 7 (1995).

11. J. Ravez and A. Simon, Mater. Lett . 36, 84 (1998).

12. A. Benziada-Taïbi, J. Ravez and P. Hagenmuller, J. Fluor. Chem. 26, 395 ( 198$) 4$.

13. J. Ravez and A. Simon, Phys. Status Solidi 159, 517 (1997).

14. J. Ravez, C. Broustera and A. Simon, J. Mater. Chem. 9, 1609 (1999).

15. J. Ravez and A. Simon, Solid State Sci. 1(1), 25 (1999).

16. J. Ravez and A. Simon, C. R. Acad. Sci. 325, 481 (1997).

17. J. Ravez and A. Simon, J. Korean Phys. Soc. 32, 955 (1998).

18. J. Ravez and A. Simon, Phys. Status Solidi 178, 793 (2000).

19. J. Ravez and A. Simon, Solid State Sci. 2(5), 525 (2005).

20. J. Ravez and A. Simon, Ferroelectrics 240, 313 (2000).

21. J. Ravez and A. Simon, J. Solid State Chem. 162(2), 260 (2001).

22. E.C. Subbarao and G. Shirane, J. Am. Ceram. Soc. 42, 279 (1954).

23. A. Simon and J. Ravez, Lead free relaxors, ed. Z.G. Ye, Cambridge (England) : Woodhead publ., (ISBN 978-1-84564186-8) (2008), pp.896-929.

24. G.A. Smolenski, V.A. Isupov and A.I. Agranovskaya, Sov. Phys. Solid State 1, 150 (1959).

25. Y.H. Bing and Z.G. Ye, J. Crystal Growth 287, 326 (2006).

26. J.G. Li, T. Ikegami and T. Mori, J. Mater. Res. 18(8), 1816 (2003).

27. C.J. Johnson, Appl. Phys. Letters 7(8), 221 (1965).

28. A. Simon, J. Ravez and M. Maglione, J. Phys.: Condens. Matter 16, 963, (2004).

29. D. Viehland, S.J. Jang and L.E. Cross, J. Appl. Phys. 68, 2916 (1990).

30. A.E. Glazounov and A.K. Tagantsev, Appl. Phys. Lett. 73, 856 (1998). 



\section{Figure}




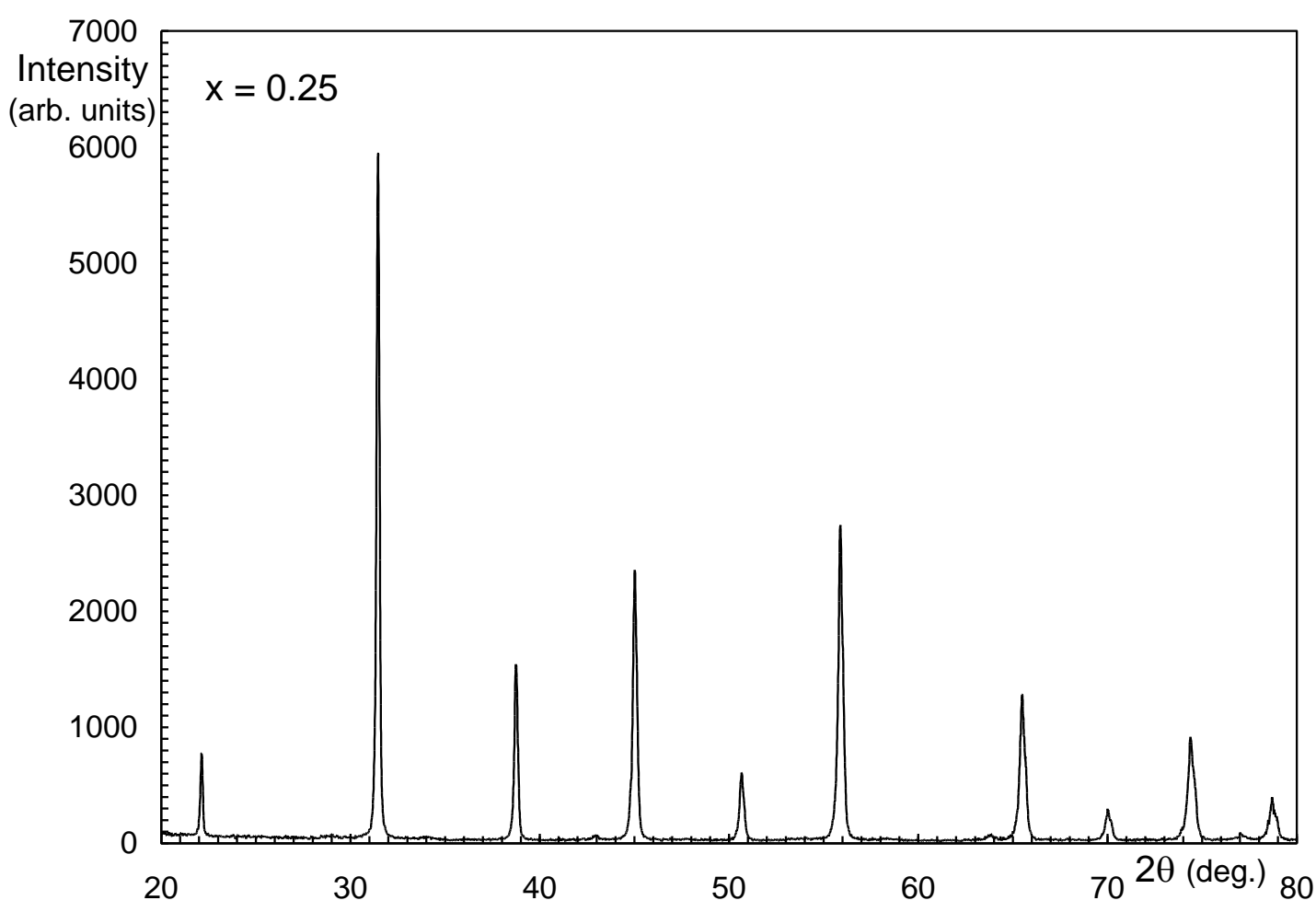

Fig. 1. X-ray powder pattern of a ceramic with composition corresponding to $\mathrm{x}=0.25$. 


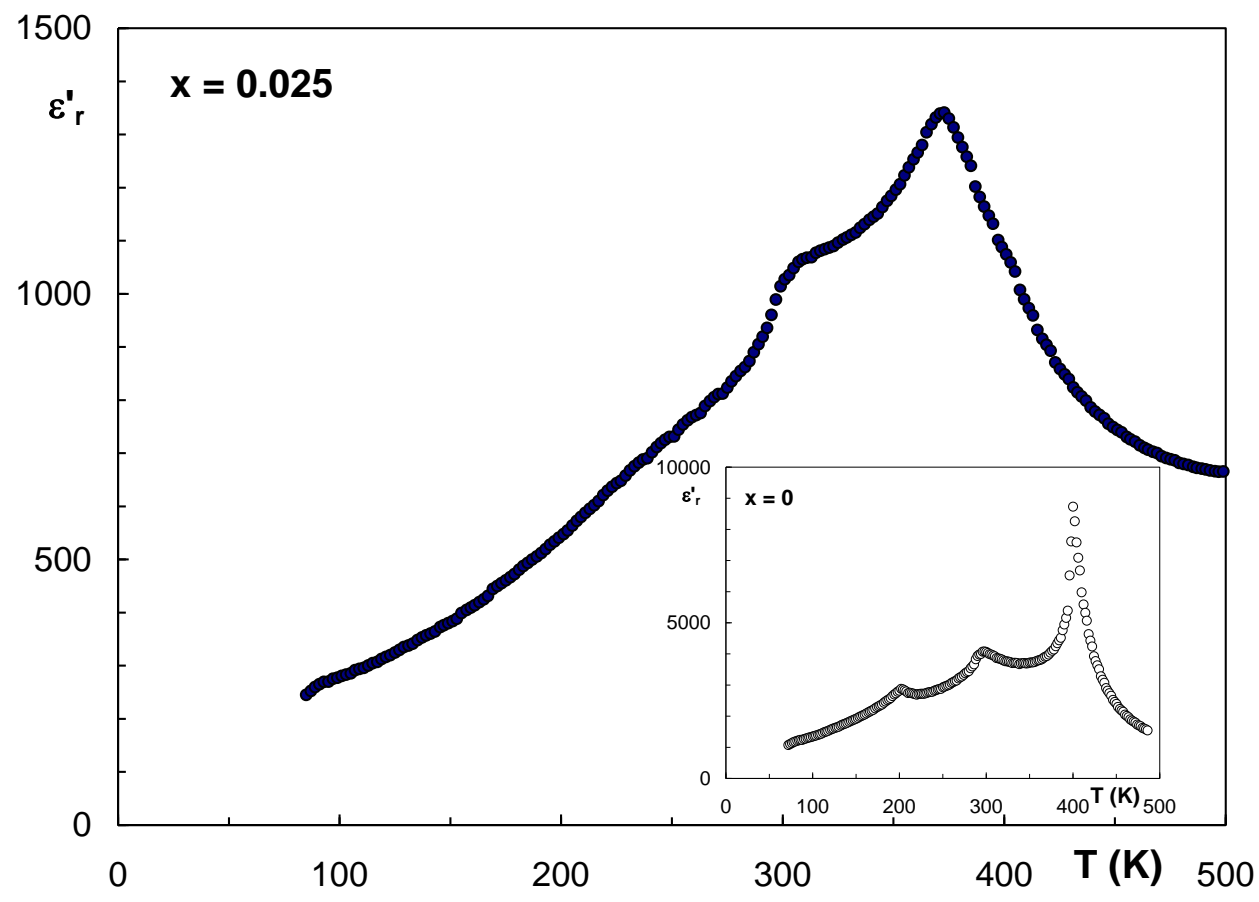

Fig. 2. Temperature dependence of $\varepsilon_{\mathrm{r}}^{\prime}$ for ceramics with compositions corresponding to $\mathrm{x}=0$ and $\mathrm{x}=0.025$ (at $1 \mathrm{kHz}$ ). 


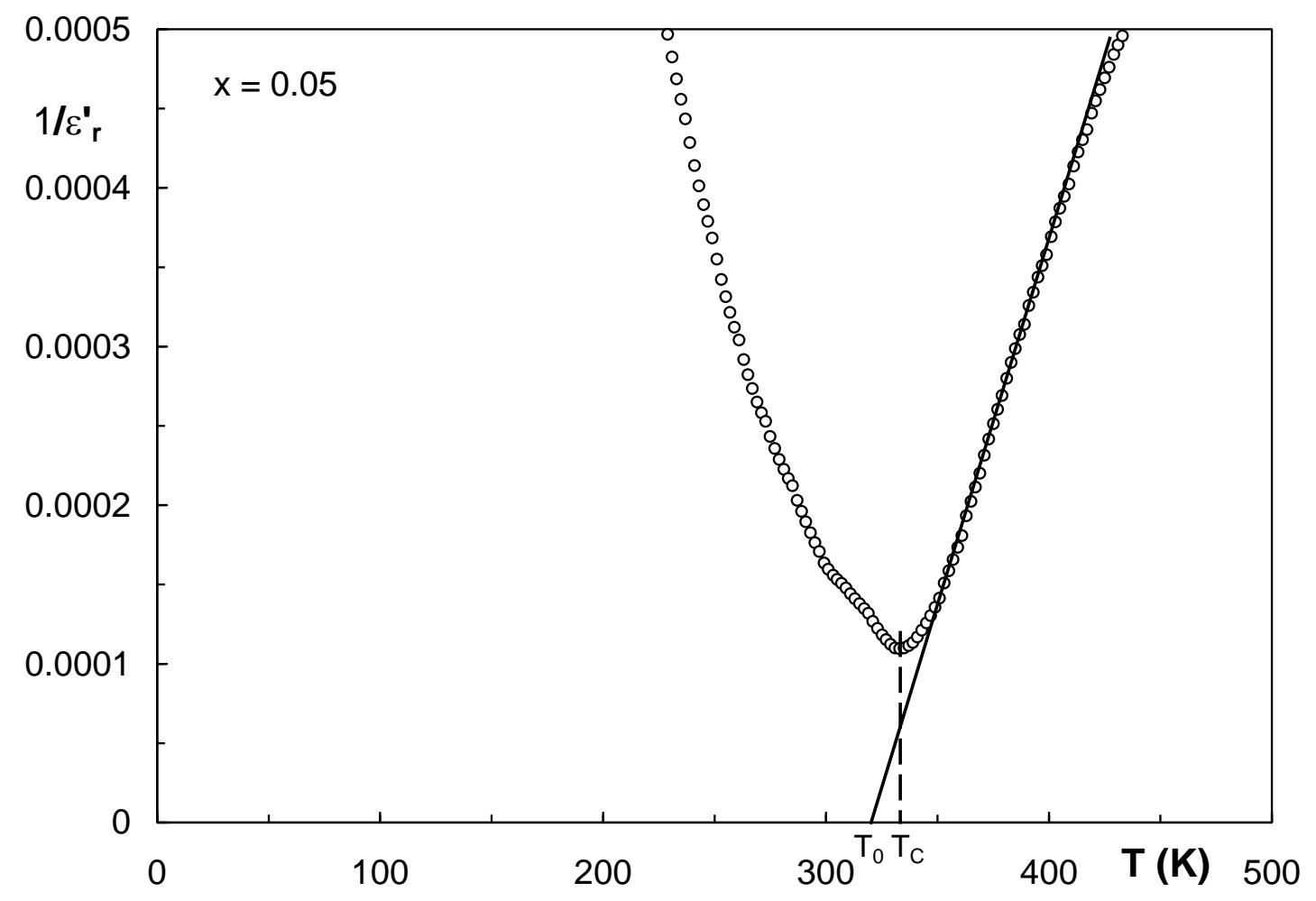

Fig. 3. Temperature dependence of $1 / \varepsilon_{\mathrm{r}}^{\prime}$ for a ceramic with composition corresponding to $\mathrm{x}=0.05$. 


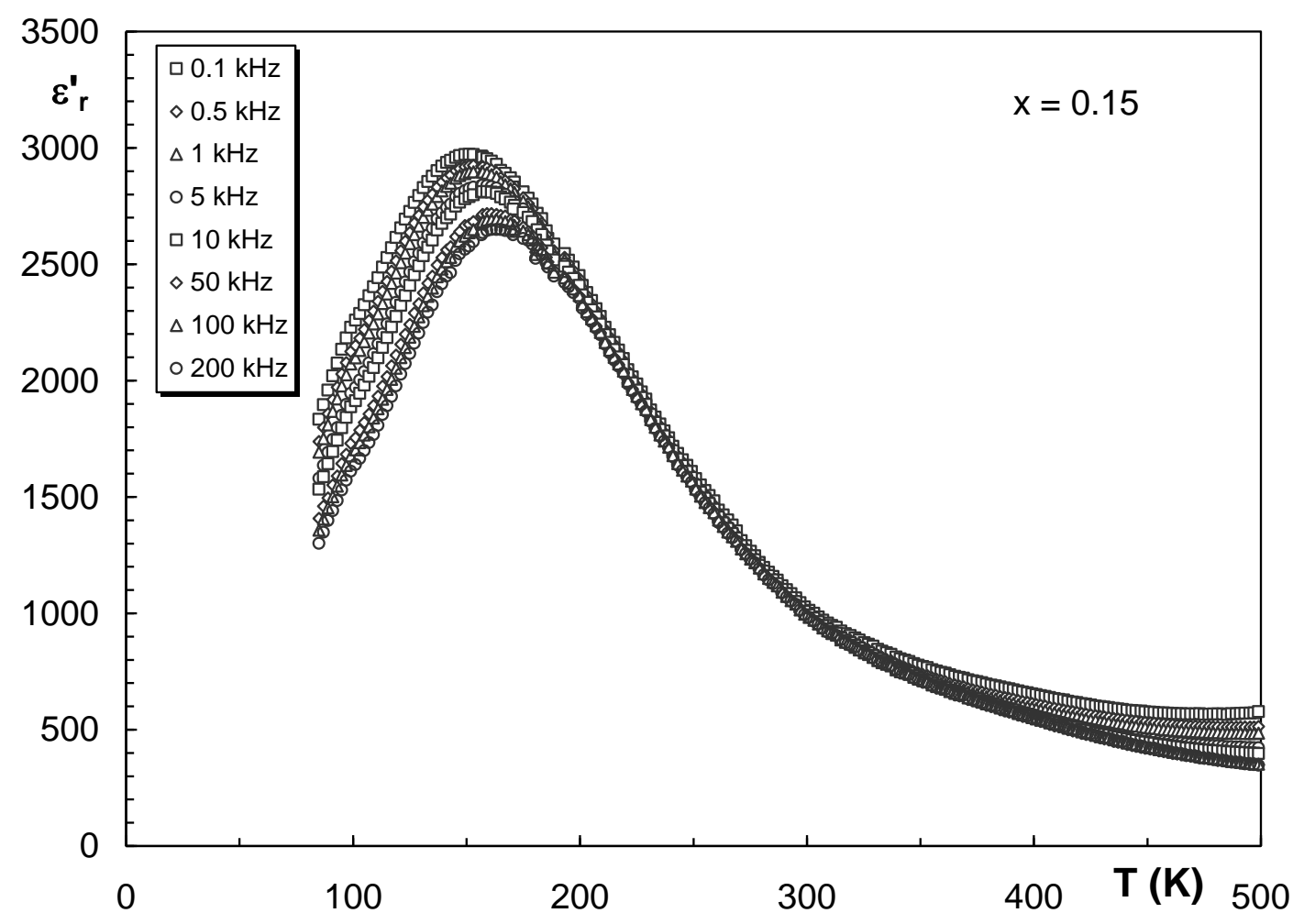

Fig. 4. Temperature dependence of the real permittivity $\varepsilon_{\mathrm{r}}^{\prime}$ for a ceramic with composition corresponding to $\mathrm{x}=0.15$. 


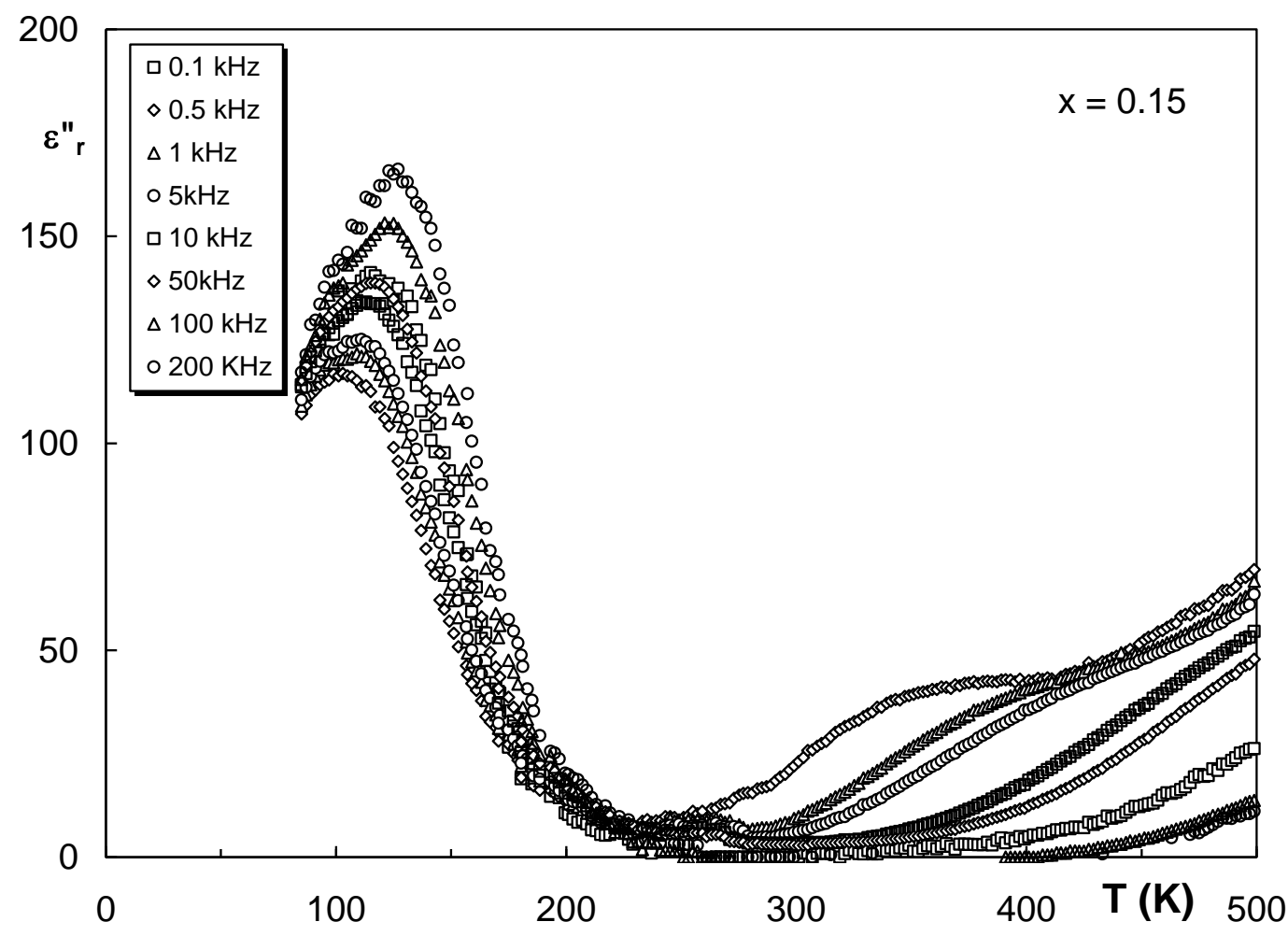

Fig. 5. Temperature dependence of the imaginary permittivity $\varepsilon^{\prime \prime}$ for a ceramic with composition corresponding to $\mathrm{x}=0.15$. 


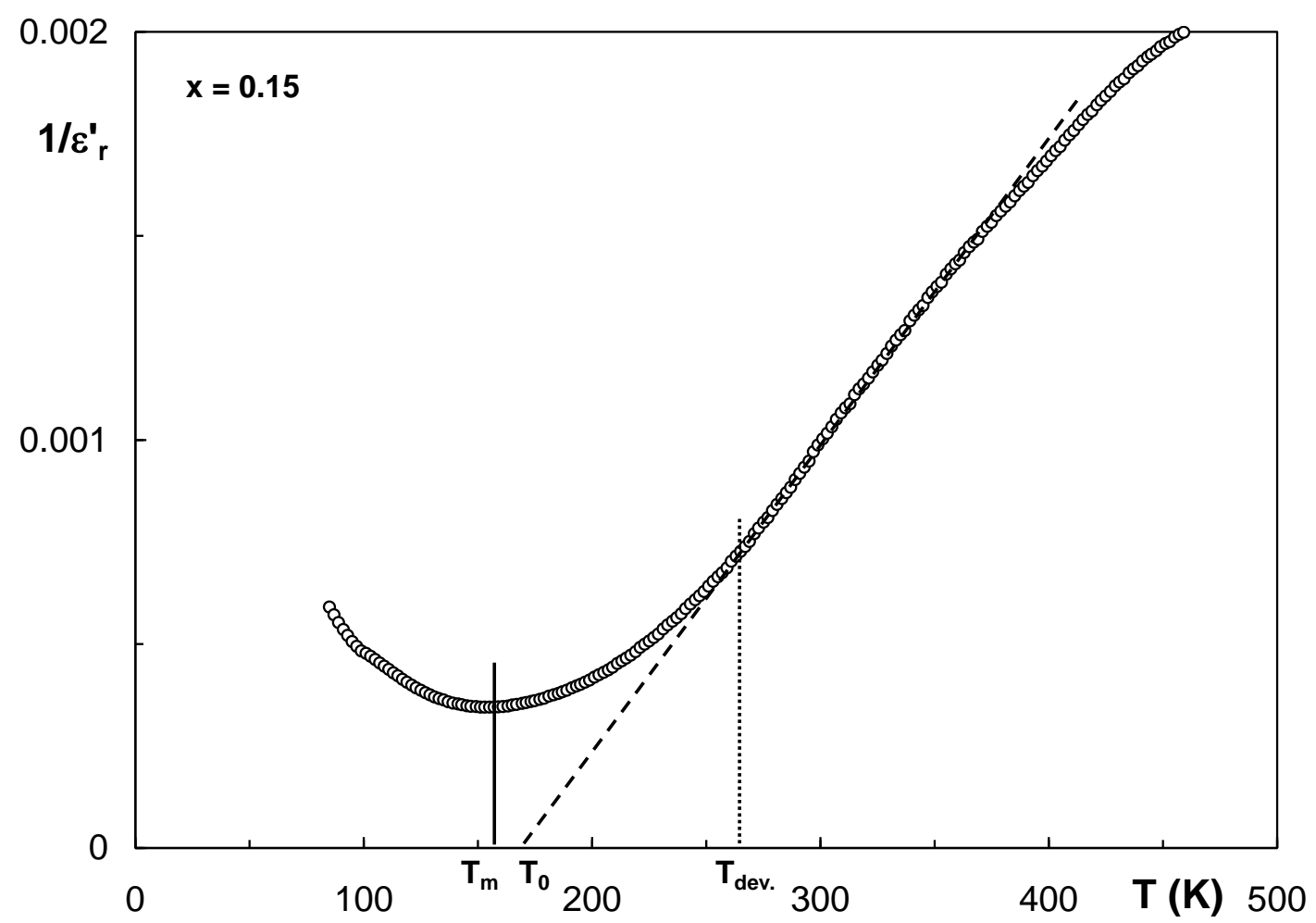

Fig. 6. Temperature dependence of $1 / \varepsilon_{\mathrm{r}}^{\prime}$ for a ceramic with composition corresponding to $\mathrm{x}=0.15$. 


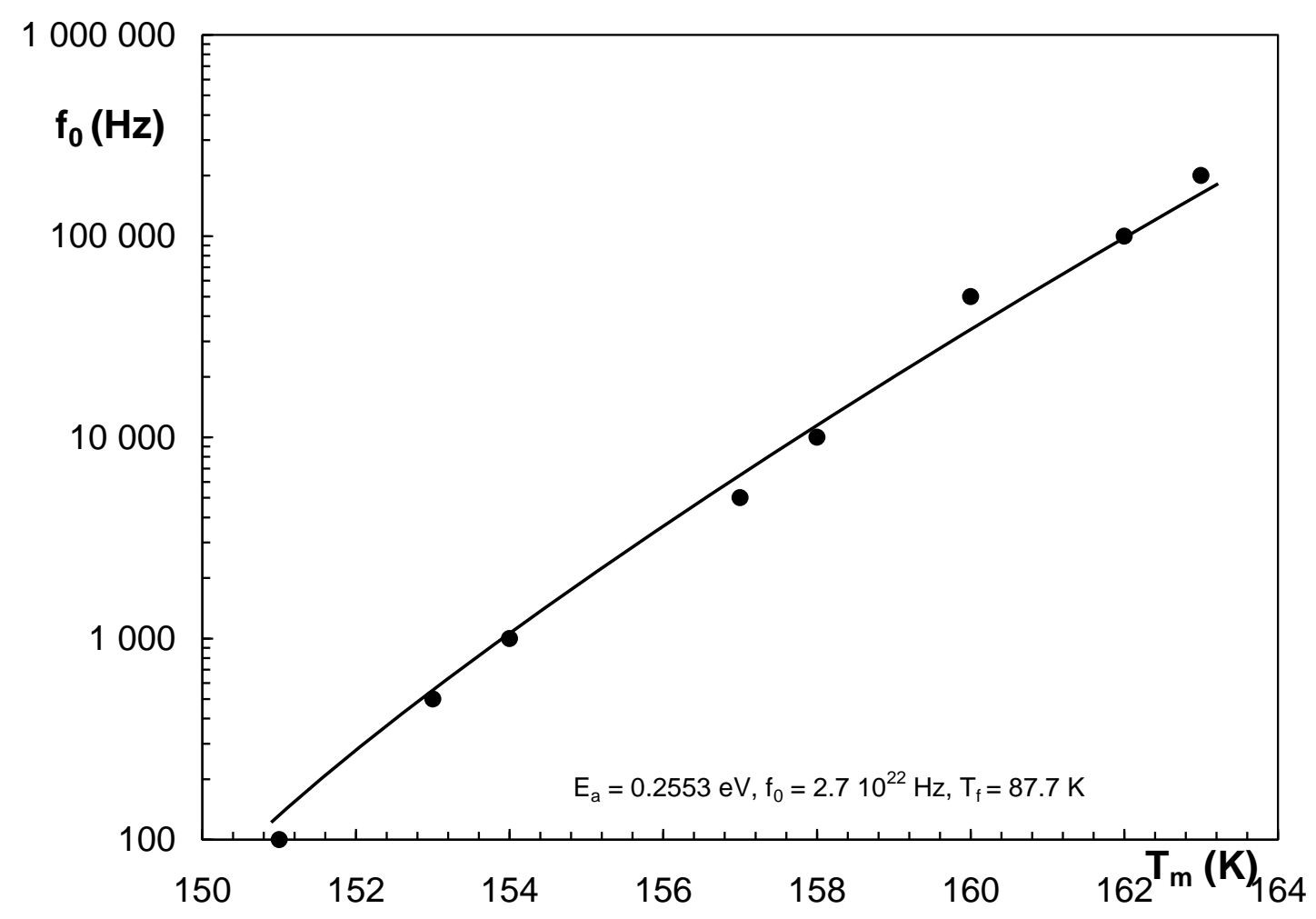

Fig. 7. Variation of $\log \mathrm{f}$ with $\mathrm{T}_{\mathrm{m}}$ for a ceramic corresponding to the composition $\mathrm{x}=0.15$. 


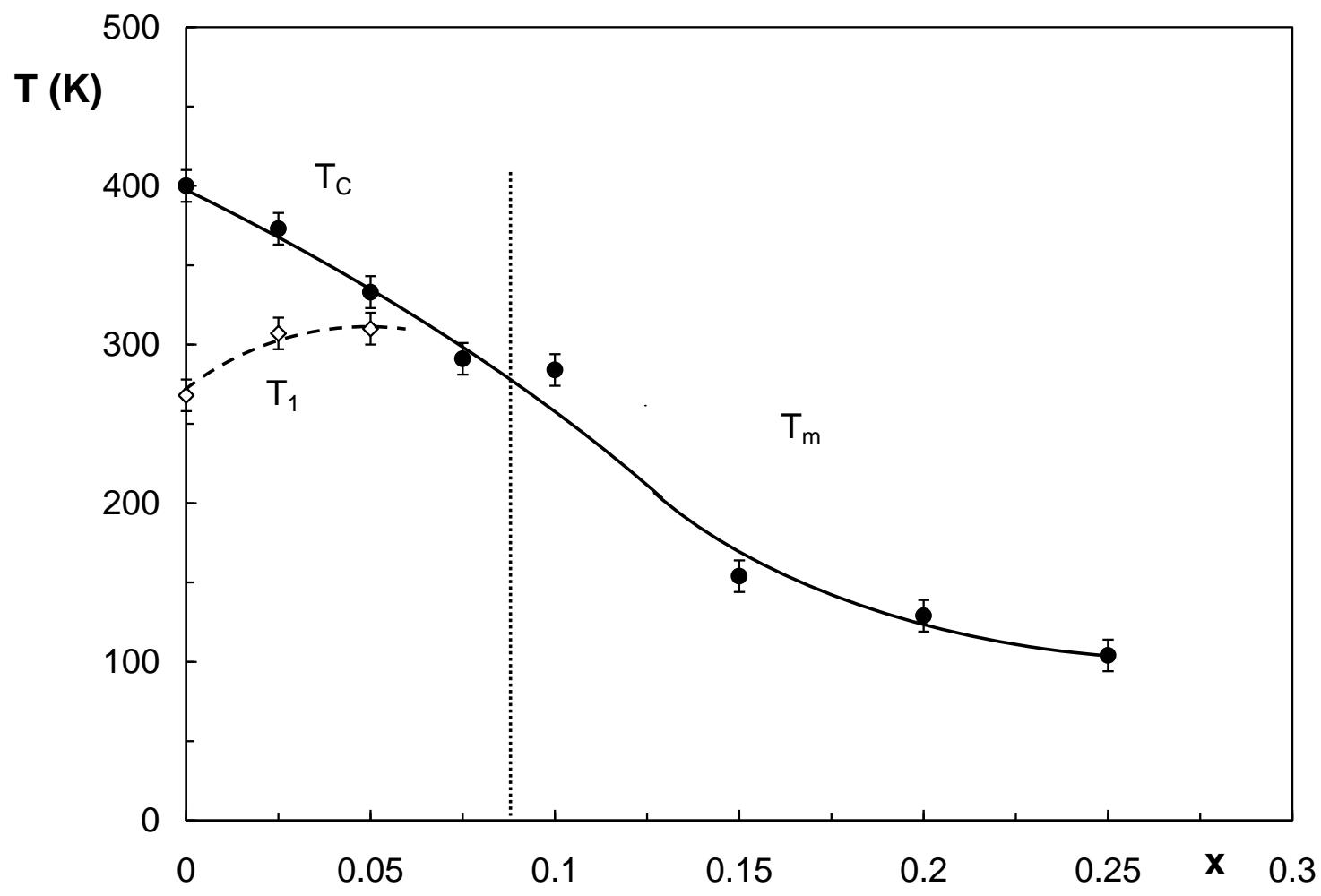

Fig. 8. Variation of $\mathrm{T}_{\mathrm{C}}$ or $\mathrm{T}_{\mathrm{m}}$ with $\mathrm{x}$ for ceramics of $\mathrm{BaTi}_{1-\mathrm{x}}\left(\mathrm{Nb}_{1 / 2} \mathrm{Sc}_{1 / 2}\right)_{\mathrm{x}} \mathrm{O}_{3}$ composition. 
